\title{
Erratum: New and Emerging Approaches to Better Define Sleep Disruption and Its Consequences
}

\author{
Frontiers Production Office* \\ Frontiers Media SA, Lausanne, Switzerland
}

Keywords: sleep disordered breathing, sleep apnea, insomnia, circadian rhythm, polysomnography, signal processing, apnea/hypopnea index, precision medicine

\section{An Erratum on:}

New and Emerging Approaches to Better Define Sleep Disruption and Its Consequences by Lechat, B., Scott, H., Naik, G., Hansen, K., Nguyen, D. P., Vakulin, A., Catcheside, P., and Eckert, D. J. (2021). Front. Neurosci. 15:751730. doi: 10.3389/fnins.2021.751730

Due to production errors, several corrections were omitted.

In "Key Components of The Polysomnographic," "K-Complexes," the sub-title should be "Kcomplexes."

In "Key Components of The Polysomnographic," "Sleep Spindles," a sentence appears as follows: "In a clinical population of 47 patients with Obstructive sleep apnea (OSA) Headers are correct

OPEN ACCESS

Approved by:

Frontiers Editorial Office,

Frontiers Media SA, Switzerland

*Correspondence:

Frontiers Production Office production.office@frontiersin.org

Specialty section:

This article was submitted to

Sleep and Circadian Rhythms, a section of the journal

Frontiers in Neuroscience

Received: 29 October 2021 Accepted: 29 October 2021 Published: 18 November 2021

Citation: Frontiers Production Office (2021) Erratum: New and Emerging Approaches to Better Define Sleep Disruption and Its Consequences. Front. Neurosci. 15:804589. doi: 10.3389/fnins.2021.804589 Confirmed, greater sleep spindle activity was associated with better implicit learning (Stevens et al., 2021)." This should instead read as follows: "In a clinical population of 47 patients with obstructive sleep apnea (OSA), greater sleep spindle activity was associated with better implicit learning (Stevens et al., 2021)."

In "Circadian Rhythms," “The Need to Assess Circadian Rhythms' to Define Sleep Disruption," a sentence appears as follows: "Chronobiological interventions, such as bright light therapy, have been administered as a stand-alone treatment and combined with CBT-I combined with CBT-I to moderate effect (Jankù et al., 2020)." This should instead read as follows: "Chronobiological interventions, such as bright light therapy, have been administered as a stand-alone treatment and combined with CBT-I to moderate effect (Jankù et al., 2020).”

The publisher apologizes for this mistake. The original version of this article has been updated.

\section{REFERENCES}

Jankù, K., Šmotek, M., Fárková, E., and Kopøivová, J. (2020). Block the light and sleep well: Evening blue light filtration as a part of cognitive behavioral therapy for insomnia. Chronobiol. Int. 37, 248-259. doi: 10.1080/07420528.2019.1692859

Stevens, D., Leong, C. W. Y., Cheung, H., Arciuli, J., Vakulin, A., and Kim, J. W. (2021). Sleep spindle activity correlates with implicit statistical learning consolidation in untreated obstructive sleep apnea patients. Sleep Med. 86, 126-134. doi: 10.1016/j.sleep.2021.01.035

Copyright $\odot 2021$ Frontiers Production Office. This is an open-access article distributed under the terms of the Creative Commons Attribution License (CC BY). The use, distribution or reproduction in other forums is permitted, provided the original author(s) and the copyright owner(s) are credited and that the original publication in this journal is cited, in accordance with accepted academic practice. No use, distribution or reproduction is permitted which does not comply with these terms. 